\title{
KAJIAN SUSEPTIBILITAS MAGNETIK PASIR BESI PANTAI ARTA SEBAGAI FUNGSI JARAK DARI TEPI LAUT
}

\author{
Irma Novalia*, Erwin \\ Jurusan Fisika Fakultas Matematika dan Ilmu Pengetahuan Alam Universitas Riau \\ *E-mail korespondensi: irmanovalia82@gmail.com
}

\begin{abstract}
Magnetic Susceptibility measurements and the identification of elements of iron sand from Arta beach of Pariaman West Sumatera have been done. The samples were dried first under the sun before the separation between magnetic particles of iron sand and non-magnetic particles using Iron Sand Separator. Identification elements of iron sand was done using X-Ray Fluorescence $(X R F)$. The total value of magnetic induction was measured using a magnetic Pasco probe PS2162 using a solenoid 2000 coils turns, dimensions of $3 \mathrm{~cm}$ in diameter and $10 \mathrm{~cm}$ in length. The solenoid was given an electric current with variations ranging from $2 \mathrm{~A}-8 \mathrm{~A}$. The distance between magnetic probe and one end of solenoid was kept constant that was $1 \mathrm{~mm}$. The next experiment was to measurement the as a function of distance ranging from $1-5 \mathrm{~mm}$ with constant applied current of $8 \mathrm{~A}$. When electric current increase then the total magnetic induction is also increase. Total magnetic induction value decrease as the distance increases. Magnetic susceptibility was calculated based on total magnetic induction and magnetic induction of core currents with constant current of $8 \mathrm{~A}$ and distance of $1 \mathrm{~mm}$. The value of magnetic susceptibility obtained in the range $(2164,71-3159,99) \times 10^{-5}$ which consist of ilmenite mineral $\left(\mathrm{FeTiO}_{3}\right.$; Antiferromagnetic).
\end{abstract}

Keywords: Iron sand, Magnetic suseptibility, Solenoid, Magnetic induction, X-ray fluorescence

\begin{abstract}
ABSTRAK
Telah dilakukan penelitian tentang penentuan nilai suseptibilitas magnetik dan identifikasi kandungan elemen dari pasir besi Pantai Arta Pariaman Sumatera Barat. Sampel dikeringkan terlebih dahulu dibawah sinar matahari sebelum dilakukan pemisahan antara partikel magnetik pasir dengan partikel non magnetik menggunakan Iron Sand Separator. Identifikasi kandungan elemen yang terdapat dalam pasir besi dilakukan menggunakan X-Ray Fluorescence (XRF). Nilai induksi magnetik total diukur menggunakan sensor probe magnetic pasco PS-2162 melalui solenoida 2000 lilitan dengan panjang $10 \mathrm{~cm}$ dan diameter $3 \mathrm{~cm}$. Solenoid ini dialiri arus listrik dengan variasi arus 2 A hingga 8 A yang jaraknya tetap $1 \mathrm{~mm}$ serta variasi jarak $1 \mathrm{~mm}$ hingga 5 $\mathrm{mm}$ dengan arus tetap $8 \mathrm{~A}$ di ujung solenoid. Ketika arus listrik dinaikkan maka nilai induksi magnetik total akan semakin besar, dan nilai induksi magnetik total berkurang apabila jarak diperbesar. Suseptibilitas magnetik $\left(\chi_{m}\right)$ dihitung berdasarkan induksi magnetik total dan induksi magnetik solenoid tanpa inti dengan arus tertentu $(8 \mathrm{~A})$ dengan jarak $1 \mathrm{~mm}$. Nilai suseptibilitas magnetik yang diperoleh terdapat pada interval $(2164,71-3159,99) \times 10^{-5}$, yaitu termasuk dalam interval mineral Ilmenite $\left(\mathrm{FeTiO}_{3}\right.$; Antiferromagnetik).
\end{abstract}

Kata kunci: Pasir besi, Suseptibilitas magnetik, Solenoid, Induksi magnetik, X-ray fluorescence

Diterima 22-07-2019| Disetujui 15-01-2020| Dipublikasi 31-03-2020

\section{PENDAHULUAN}

Pasir besi adalah sejenis mineral yang berpotensi memiliki nilai ekonomis tinggi karena mengandung unsur besi, titanium, dan unsur lainnya yang bisa dimanfaatkan sebagai target dalam bahan industri [1]. Pasir besi sebagian besar terdapat di sepanjang pantai pulau-pulau besar di Indonesia seperti pantai Pulau Jawa, Kalimantan, Sulawesi, Irian Jaya, dan pantai barat Pulau Sumatera [2]. 
Pasir besi mengandung $73 \%$ besi oksida seperti magnetite $\left(\mathrm{Fe}_{3} \mathrm{O}_{4}\right)$, hematite $\left(\alpha-\mathrm{Fe}_{2} \mathrm{O}_{3}\right)$, maghemite $\left(\gamma-\mathrm{Fe}_{2} \mathrm{O}_{3}\right)$, limonite $\left(2 \mathrm{FeO}_{3} \cdot \mathrm{nH}_{2} \mathrm{O}\right)$ serta $16 \%$ titanium oksida seperti ilmenite $\left(\mathrm{FeTiO}_{3}\right)$ yang merupakan mineral magnetik. Magnetite adalah salah satu mineral yang paling dominan dalam pasir besi memiliki ciri berwarna hitam, hematite memiliki ciri berwarna merah, sedangkan maghemite memiliki ciri yang berwarna kecoklatan [3]. Partikel magnetik khusus $\mathrm{Fe}_{3} \mathrm{O}_{4}$ dalam ukuran nanometer memiliki sifat yang unik yaitu sifat superparamagnetik, dimana partikel ini memiliki koersivitas yang kecil namun memiliki magnetik momen yang sangat tinggi [4].

Keberadaan pasir besi disepanjang pantai Sumatera Barat memiliki potensi pengembangan pertambangan dengan kadar besi $2 \%$ sampai dengan $7 \%$ yang ketebalannya bervariasi antara $2 \mathrm{~mm}$ sampai dengan $10 \mathrm{~mm}$ [5], sementara itu pasir besi di pinggir pantai Sumatera Barat khususnya Pantai Arta Pariaman belum banyak dimanfaatkan.

Penelitian sebelumnya seperti penelitian oleh David (2017) dan Filza (2018) telah melakukan penentuan terhadap suseptibilitas magnetik pasir besi dengan menggunakan teknik kumparan (solenoid), memperoleh bahwa nilai suseptibilitas magnetik sampel dalam interval ilminite $\left(\mathrm{FeTiO}_{3}\right)$ dengan tingkat kemagnetan berada pada interval $(0,5-$ 2). Partikel magnetik memiliki sifat magnetik yang dapat dikontrol apabila menggunakan medan magnet luar dan aplikasinya sangat luas seperti media penyimpan data, sensor magnetik [6], partikel pembawa obat [7], biomedis[8], biosensor [9], dan sebagai partikel pembersih air dari polutan [10].

Metode untuk sintesis nanopartikel magnetik diantaranya terdiri dari metode fisika [10], metode kimia [11], dan biologi [12]. Ditinjau dari luasnya aplikasi partikel magnetik maka potensi pasir besi dari pantai Arta Pariaman perlu ditingkatkan dengan melakukan preparasi partikel magnetik untuk mengetahui sifat magnetik yang terdiri dari induksi magnetik, suseptibilitas magnetik, suseptibilitas massa, tingkat kemagnetan serta kandungan komposisi mineral magnetik sehingga dapat dimanfaatkan dan memiliki nilai tambah pada bidang ekonomi.

\section{METODE}

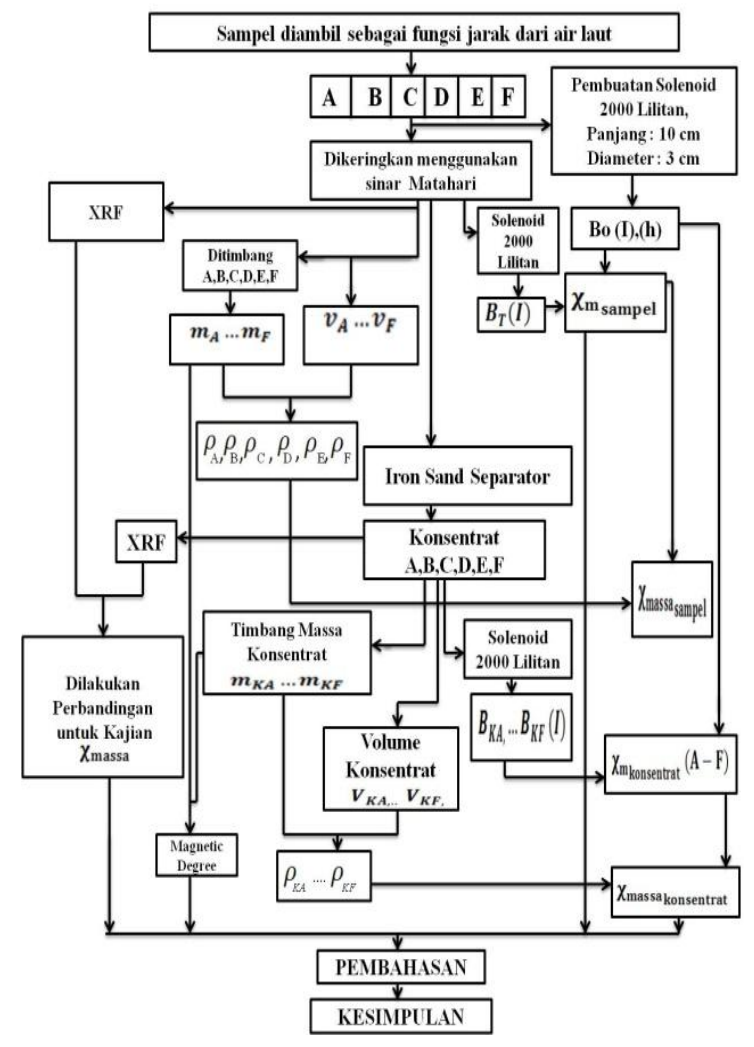

Gambar 1. Skema prosedur penelitian.

Prosedur penelitian dilakukan 2 tahap yaitu pengambilan sampel dan proses laboratorium seperti pada Gambar 1 yaitu :

1. Sampel dalam penelitian ini diambil dari Pantai Arta Sumatera Barat

2. Proses laboratorium yaitu :

a) Solenoid yang digunakan adalah 2000 lilitan.

b) Sampel yang telah diambil dibawa ke Laboratorium Instrumentasi dan Magnetik Jurusan Fisika Universitas Riau untuk dikeringkan dibawah sinar matahari sampai keadaan kering selama 3 hari.

c) Sampel yang telah dikeringkan lalu dilakukan penimbangan agar mengetahui massa sebelum pemisahan antara sampel dengan partikel magnetiknya 
d) Sampel yang telah ditimbang selanjutnya diproses menggunakan Iron Sand Separator untuk memisahkan sampel dengan partikel magnetiknya.

e) Sampel yang telah dipisahkan menggunakan Iron Sand Separator akan menghasilkan konsentrat partikel magnetik.

f) Sampel sebelum pemisahan dan konsentrat setelah pemisahan tersebut akan diuhi menggunakan XRF agar mengetahui komposisi atau kandungan elemen dari pasir besi tersebut.

\section{HASIL DAN PEMBAHASAN}

Hasil pengukuran dari penelitian ditampilkan dalam bentuk tabel dan grafik.

\section{Sifat Magnetik}

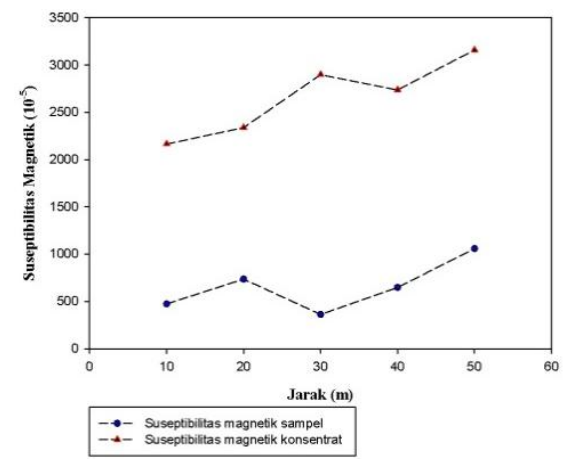

Gambar 2. Grafik perbandingan nilai suseptibilitas magnetik sampel sebelum pemisahan dan suseptibilitas magnetik konsentrat setelah pemisahan menggunakan Iron Sand Separator.

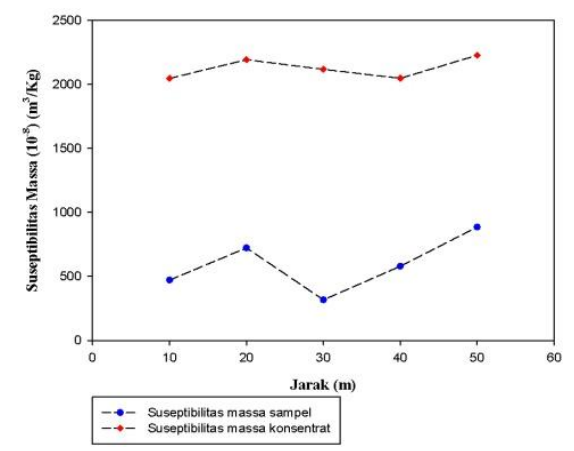

Gambar 3. Grafik perbandingan nilai suseptibilitas massa sampel dan suseptibilitas massa konsentrat.

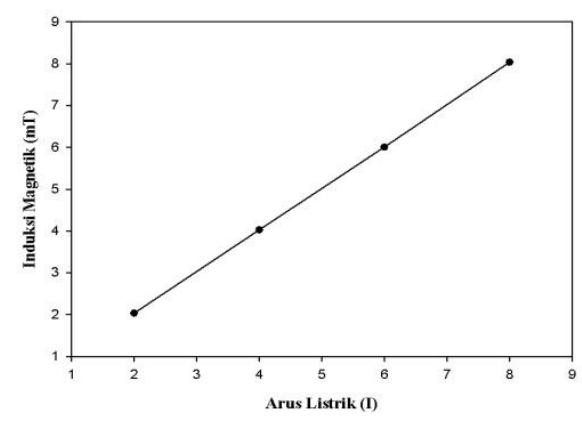

Gambar 4. Grafik hubungan antara induksi magnetik solenoid tanpa inti dengan fungsi arus (I) pada jarak tetap $(1 \mathrm{~mm})$ dari ujung solenoid.

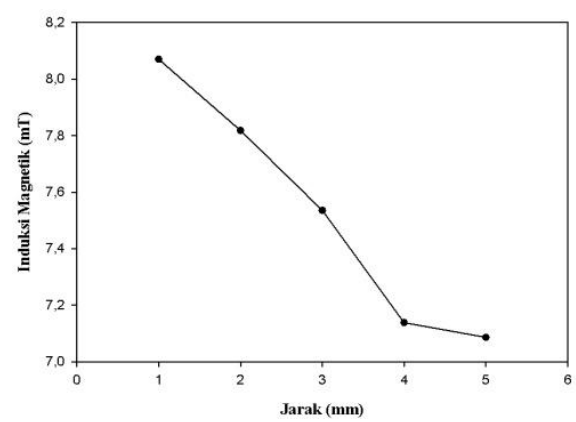

Gambar 5. Grafik hubungan antara induksi magnetik solenoid tanpa inti untuk arus konstan (8 A) dengan jarak variasi.

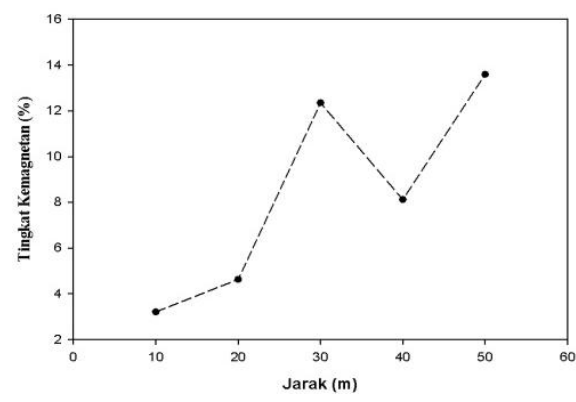

Gambar 6. Grafik nilai tingkat kemagnetan masing-masing titik lokasi sampel.

\section{Uji X-Ray Fluorescence}

Identifikasi komposisi pasir besi dapat dilihat pada Tabel 1 dan 2 yang menampilkan hasil identifikasi elemen sampel pasir besi pantai Arta Sumatera Barat sebelum dan sesudah diproses menggunakan Iron Sand Separator, dapat dilihat bahwa kandungan elemen $\mathrm{Fe}$ meningkat setelah pemisahan menggunakan Iron Sand Separator yaitu dari $6,118 \%$ menjadi $42,245 \%$ begitu juga terhadap Ti dan Mn. Peningkatan nilai kandungan elemen menunjukkan bahwa elemen-elemen 
tersebut mengandung unsur magnetik. Sementara itu, terjadi penurunan konsentrasi terhadap $\mathrm{Si}, \mathrm{Mg}, \mathrm{Al}, \mathrm{P}, \mathrm{K}, \mathrm{Ca}$, dan $\mathrm{V}$. Penurunan ini menunjukkan bahwa elemen tersebut tidak mengandung unsur magnetik.

Tabel 1. Hasil identifikasi pasir besi sebelum diproses Iron Sand Separator.

\begin{tabular}{lll}
\hline No & Elemen & Komposisi (\%) \\
\hline 1 & $\mathrm{Mg}$ & 3,452 \\
2 & $\mathrm{Al}$ & 10,706 \\
3 & $\mathrm{Si}$ & 61,182 \\
4 & $\mathrm{P}$ & 0,908 \\
5 & $\mathrm{Cl}$ & 2,415 \\
6 & $\mathrm{~K}$ & 7,245 \\
7 & $\mathrm{Ca}$ & 5,835 \\
8 & $\mathrm{Ti}$ & 0,472 \\
9 & $\mathrm{~V}$ & 0,006 \\
10 & $\mathrm{Mn}$ & 0,136 \\
11 & Fe & 6,118 \\
12 & Elemen lain & 1,519 \\
\hline
\end{tabular}

Tabel 2. Hasil identifikasi pasir besi setelah di proses Iron Sand Separator.

\begin{tabular}{lll}
\hline No & Elemen & Komposisi (\%) \\
\hline 1 & $\mathrm{Mg}$ & 3,376 \\
2 & $\mathrm{Al}$ & 8,923 \\
3 & $\mathrm{Si}$ & 33,021 \\
4 & $\mathrm{P}$ & 0,652 \\
5 & $\mathrm{Cl}$ & 2,645 \\
6 & $\mathrm{~K}$ & 1,355 \\
7 & $\mathrm{Ca}$ & 2,135 \\
8 & $\mathrm{Ti}$ & 3,658 \\
9 & $\mathrm{~V}$ & 0,326 \\
10 & $\mathrm{Mn}$ & 0,137 \\
11 & $\mathrm{Fe}$ & 42,245 \\
12 & Elemen lain & 1,527 \\
\hline
\end{tabular}

\section{KESIMPULAN}

Berdasarkan data hasil penelitian yang telah dilakukan maka dapat diambil kesimpulan sebagai berikut. Nilai suseptibilitas magnetik dan suseptibilitas massa serta induksi magnetik semakin meningkat ketika jarak pengambilan sampel dari tepi laut semakin jauh, secara keseluruhan nilai suseptibilitas magnetik berada dalam interval $200-380.000 \times 10^{-5}$ dan nilai suseptibilitas massa sampel berada dalam interval $46-80000 \times 10^{-8} \mathrm{~m}^{3} / \mathrm{Kg}$ yang merupakan interval mineral Ilmenite Berdasarkan uji XRF komposisi elemen Fe semakin meningkat disebabkan oleh kurangnya elemen non magnetik seperti $\mathrm{Si}$, $\mathrm{Mg}, \mathrm{Al}, \mathrm{Ca}$, dan elemen lainnya.

\section{REFERENSI}

1. Bates \& Jackson. (1980). Glossary of Geology. American Geological Institute.

2. Prasetyo, A. \& Mahardika. (2008). Kajian Magnetik $\left(\mathrm{Fe}_{2} \mathrm{O}_{3}\right)$ Hasil Penumbuhan dengan Metode Prespitalasi Berbahan Dasar Pasir Besi. Tesis Ilmu Kemagnetan, Institut Teknologi Bandung.

3. Yulianto, A., Bijaksana, S., \& Loeksmanto, W. (2002). Karakteristik Magnetik dari Pasir Besi Cilacap. Jurnal Fisika Himpunan Fisika Indonesia, A5(0527), 1-4.

4. Srivastava, A., Ojha, A., Chaubey, S., Singh, J., \& Sharma, P. (2010). Investigation on Magnetic Properties of $\alpha$ $\mathrm{Fe}_{2} \mathrm{O}_{3}$ Nanoparticles Synthesized under Surfactant-Free Condition by Hydrothermal Process. Journal Of Alloys and Compounds, 500, 206.

5. Sektor Pertambangan Sumbarprov. (2014). Diakses pada 14 Maret 2018, URL: http://www.sumbarprov.goi.id/details/new s/2700.

6. Zeng, H., Li, J., Liu, J. P., Wang, Z. L., Sun, S. H. (2002). Nature, 420, 395.

7. Feng, B., Hong, R. Y., Wang, L. S., Guo, L., Li, H. Z., Ding, J., Zheng, Y., \& Wei, D. G. (2008). Colloids Surfaces A Physicochem. Eng. Asp., 328, 52.

8. Cao, X., Zhang, B., Zhao, F., \& Feng, L. (2012). Synthesis and Properties of MPEG-Coated Super paramagnetic Magnetite Nanoparticles. J. Nanomater., 2012, 1-6. 
9. Anbarasu, M., Anandan, M., Chinnasamy, E., Gopinath, V., \& Balamurugan, K. (2015). Spectrochim. ACTA Part A Mol. Biomol. Spectrosc., 135, 536.

10. Mahmoudi, M., Sant, S., Wang, B., Laurent, S., \& Sen, T. (2011). Superparamagnetic iron oxide nanoparticles (SPIONs): development, surface modification and applications in chemotherapy. Advanced Drug Delivery Reviews, 63(2011), 24-46.
11. Massart, R. \& Cabuil, V. (1987). Effect of some parameters on the formation of colloidal magnetite in alkaline-mediumyield and particle-size control. Journal of Chemical Physic, 84(1987), 967-973.

12. Indira, T. K. \& Lakshmi, P. K. (2010). International Journal of Pharmaceutical Sciences and Nanotechnology, 3, 10351042. 